\section{AN IMPROVED UTERINE CLAMP AND RETRACTOR}

A. MILES 'TATLOR, M.D.

SAN FRANCISCO

The clamp illustrated is one which I have devised, believing that it will serve the purpose for which it is intended better than any clamp heretofore available. I find it very useful in al] cases in which it is desired to elevate and hold $u p$ the uterus. Being devoid of teeth it does not injure or macerate the parts. The curves of the instrument allow it to fit around the uterus and it is not in the way in operating on the uterus or appendages from any side. In some cases it may be used as a
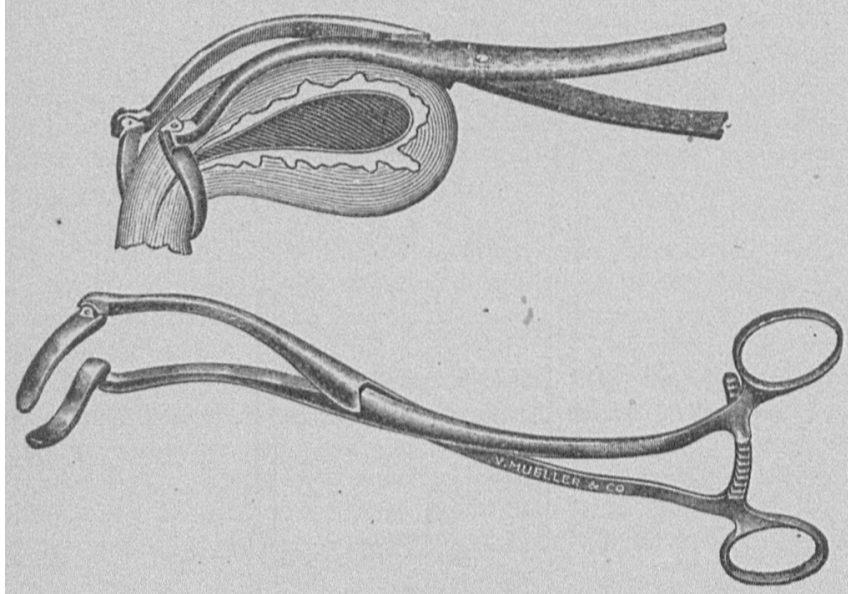

The uterine clamp and retractor, showing it applied to the uterus.

retractor. The jaws of the instrument are bent 80 as to grasp and surround the neck of the uterus without in any way injuring it. The jaws being on a swivel are not apt to produce sufficient pressure to do damage.

I have used the instrument in abdominal hysterectomies, removal of the appenduges, in operations for ovarian lesions, shortening of the round ligaments, ventral fixation, removal of interstitial and subperitoneal fibromyomas, and in bringing up the uterus to expose the bladder.

\section{Therapeutics}

TIIE LOCAL APPLICATION OF DRY HOT AIR

The general practitioner will never be able to apply personaliy the major elements of physiologic therapy to any great extent because of the elaborateness of the plant required, but some of the minor elements can be perfectly utilized by the general practitioner, and most gratitying therapeutic results obtained. The local application of dry hot air is one of the most useful of them.

'There are on the niarket several forms of apparatus for its application, all of which will do good work. In order to be efficient an apparatus must be capable of producing 400 degrees Fahrenheit in fifteen minutes at the outside, and of maintaining this temperature indefinitely. In order to be useful to the general practitioner these machines must also be easily portable. They may be heated by gas, gasoline, alcohol, or electricity, but one that is to be used in general practice should be supplied with a gasoline attachment, whatever other heating agent is usually employed, as the gas-pressure in some houses is not sufficient to produce an adequate degree of heat, electricity is available in only a few houses, and al ohol is not generally satisfactory for several reasons.
Preparation of the patient for the application is simple, consisting merely in covering the part of the body to be treated with three thicknesses of loose-meshed Turkish toweling, so as to secure intimate contact between wrapping and slin. If the perspiration which is induced as soon as the heat strikes the skin, is allowed to remain on the skin during a treatment, it will soon boil under the influence of the intense heat and blister the patient. These wrappings absorb it as soon as it is formed, the heat immediately vaporizes it and it rapidly diffuses itself out of the wrapping.

Directions for the general operation of the machines, are furnished by the manufacturers. Complete treatises on thermaerotherapy can be obtained by those who take more than a passing interest in it.

The physiologic effect of the dry hot-air application is produced in two ways: first, by thermic irritation of the numerous nerve-endings in the skin, and second, by the actual raising of the temperature of those portions of the body in immediate contact with the heat.

Irritation of the nerve-endings of the skin results. by reflex action, in (1) marked dilatation of the capillary areas, hence greatly increased blood-supply. (2) enormously increased functionation of the sweat-glands, hence increased local elimination, and (3) acceleration of the cell mutrition and function through reflex stimulation of the spinal centers. The raising of the temperature, en masse, results in acceleration of the chemical reactions constituting the cell metabolisn of the part. It will be observed that the combination of these jufluences result in increased physiologic resistance of the tissues affected and acceleration of the process of repair of damaged tissue elements.

The sphere of action of this application, then, is in the treatment of pathologic conditions which are strictly local in character, and which ean be happily influenced by increasing the local physiologric cell resistance and the local nutritional, absorptive, and eliminative functions. Such conditions obtain in many disenses encountered by the general practitioner but it will suffice to mention three which illustrate the difierent types of cases in which the local dry hot-air application is most useful. These three are (1) sprains, (2) most cases of true rheumatism in which but one or two joints are involved, and (3) local septic infection of the extremities before the process has involved the lymphatics connecting the affected part with the trunk, and in which the general toxemia resulting from the local lesion is not profound enough to overwhelm the organism as a whole.

\section{BPRAINS}

In an uncomplicated sprain the lesion consists simply of a traumatic solution of the continuity of soft tissues about the affected joint, accompanied by severe pain proluably due to congestive irritation of lacerated nerve fibcrs. The therapeutic indications are (1) to relicve pain, (2) so to influence the trophic functions as to secure the quickest possible repair, and (3) to promote absorption of the exudate.

Increase in the physiologic resistance of cells is not. called for in this condition, but acceleration of the nutritional, absorptive and eliminative processes are indicated; practically clinical experience demonstrates that the local dry hot-air treatment is well qualified to satisfy the requirements. If a sprain is put under treatment by this agent within three or four hours after the injury has been sustained, the pain will be relieved within half an hour, and all traces of the trouble will usually bave disappeared within forty-cight hours. If the case is 